\title{
Enzymatic Digestion and Mass Spectrometry in the Study of Advanced Glycation End Products/Peptides
}

\author{
Annunziata Lapolla, Domenico Fedele, Rachele Reitano, \\ and Nadia Concetta Aricò \\ Dipartimento di Scienze Mediche e Chirurgiche, Cattedra di Malattie del Metabolismo, Università degli Studi \\ di Padova, Padova, Italy
}

Roberta Seraglia and Pietro Traldi

CNR, Istituto di Scienze e Tecnologie Molecolari, Sezione di Padova, Corso Stati Uniti 4, Padova, Italy

\author{
Ester Marotta
}

CNR, INTM, Sezione di Padova, Dipartimento di Chimica Organica, Università di Padova, Padova, Italy

\author{
Roberto Tonani \\ Pharmacia Italia S.p.A., Milano, Italy
}

\begin{abstract}
An extensive study was carried out on HSA and non-enzymatically glycated HSA by enzymatic digestion with trypsin and endoproteinase Lys-C, with the aim of identifying specific glycated peptides deriving from enzymatic digestion of glycated HSA. They may be considered, in pectore, as advanced glycation end products/peptides. These compounds, important at a systemic level in diabetic and nephropathic subjects, are produced by enzymatic digestion of in vivo glycated proteins: They are related to the pathological state of patients and have been invoked as responsible for tissue modifications. The digested mixtures obtained by the two enzymes were analyzed by MALDI/MS and LC/ESI/MS ${ }^{n}$, and clear cut differences were found. First of all, the digestion products of glycated HSA are generally less abundant than those observed in the case of unglycated HSA, accounting for the lower proclivity of the former to enzymatic digestion. MS/MS experiments on doubly charged ions, comparisons with a protein database, and molecular modeling to identify the lysine $\mathrm{NH}_{2}$ groups most exposed to glycation, identified some glycated peptides in digestion mixtures obtained from both types of enzymatic digestion. Residues ${ }^{233} \mathrm{~K},{ }^{276} \mathrm{~K},{ }^{378} \mathrm{~K},{ }^{545} \mathrm{~K}$, and ${ }^{525} \mathrm{~K}$ seem to be privileged glycation sites, in agreement with the fractional solvent accessible surface values calculated by molecular modeling. (J Am Soc Mass Spectrom 2004, 15, 496-509) (c) 2004 American Society for Mass Spectrometry
\end{abstract}

$\mathrm{D}$ iabetes is a widespread disease, involving about $4 \%$ of the entire world population. For this reason, many efforts have been devoted to the wide application of valid monitoring procedures and to the development of effective therapeutic approaches. Although these efforts have led to reduced mortality, mainly related to optimized control of the acute complications of the disease (hypoglycemic coma, ketoacidosis, infections), the long-term complications of diabetes (macroangiopathy, nephropathy, retinopathy, neuropathy) still remain widespread and constitute a

Published online February 2, 2004

Address reprint requests to Dr. P. Traldi, Area della Ricerca, Corso Stati Uniti 4, CNR-ISTM, Padova 35127, Italy. E-mail: pietro.traldi@adr.pd.cnr.it hallmark both for patients and from the social viewpoint.

The first effect of the high glucose concentration in biological fluids, typical of diabetes, is non-enzymatic protein glycation. When a protein undergoes high glucose concentration, a reaction between either terminal or lysine- $\varepsilon$ amino groups and glucose takes place. This reaction, originally studied by Maillard [1, 2], leads to the production of glycated proteins which, to some extent, can release the chemically modified sugar moiety, leading to the formation of highly reactive species called "Advanced Glycation End Products" (AGE) [3].

In turn, AGE can react with other proteins, leading to chemically altered species which can activate crosslinking reactions [4]. These reactive species can also interact at the cellular level with specific receptors 
inducing undesired cell responses responsible for inflammatory reactions reflected in tissue damage [5]. These chemical pathways can be invoked to explain the tissue modifications typical of long-term diabetic complications [6].

High circulating AGE levels are due either to their high production (as in diabetes) or to impaired kidney excretion (as in chronic renal failure) [7].

Hence, high AGE concentrations reflect the production of AGE-modified proteins which, being chemically altered, show different biological activity, activating a macrophage response with consequent internalization and digestion [8]. AGE-modified proteins can then generate a series of AGE-modified and highly reactive peptides, which react with plasma lipoprotein (lowdensity lipoprotein, LDL) to form AGE-modified LDL and cross-links with collagen. Thus, AGE peptides exhibit the same toxic activity as AGEs and, consequently, are invoked as responsible for the tissue modifications typical of complications of diabetes and chronic renal failure [9].

Studies on AGE peptides are consequently of great interest and lead to the identification of chemical species related to patients' pathological conditions. Their identification must necessarily be considered from the structural point of view because, once their structures have been defined, their origin can also be defined and pharmacological approaches can be designed.

In view of the great complexity of plasma, direct identification of AGE peptides in this substrate is certainly a difficult task. Consequently, it was believed of interest to start from some in vitro experiments, based on in vitro non-enzymatic glycation of proteins of known structure, followed by their enzymatic digestion.

The analytical approach used in early researches in this framework mainly applied liquid chromatography [10]. Clearcut differences were found between the digestion mixtures of glycated and unglycated proteins but no structural information on the species present in the case of glycated proteins could be obtained. Highly specific techniques are required and thus mass spectrometry, particularly the latest techniques devoted to proteome, seemed to be suitable. In a first application of this approach, bovine serum albumin (BSA) was glycated in vitro, following Gugliucci and Bendayan [10] and digested by proteinase $\mathrm{K}$ [11]. The digestion mixture was very complex due to the high enzymatic activity. Comparisons of LC/ESI/MS chromatograms of digested samples from glycated and unglycated proteins revealed definite differences and the molecular weights of some species only present in glycated BSA were easily determined. Some structural information was gained from MS/MS experiments but, due to the extensive action of the enzyme, no definitive structural results were obtained.

For more specific results, in a further study [12] human serum albumin (HSA) was glycated in vitro and a more specific enzyme was employed for its digestion.
LC/ESI/FTMS was also used as analytical approach, identifying about 20 glycated peptides. Their structures were postulated on the basis of accurate mass measurements and on the known sequence of HSA [13]. Interestingly, some cross-linking products were identified among them, indicating the occurrence of intra-molecular cross-links. Another point highlighted in that study was the yield of digestion products of glycated HSA, which was lower than that observed in unglycated protein. This fits the medical hypothesis, i.e., that glycated proteins are more difficult to digest enzymatically and consequently accumulate at a systemic level.

For further structural information, we undertook the present study, based on two different types of enzymatic digestion, i.e., trypsin and endoproteinase Lys-C (Lys-C) of glycated HSA, and on comparisons with the digestion products of unglycated protein. In order to obtain information on the preferential glycation sites of the protein, LC/ESI/MS ${ }^{\mathrm{n}}$ experiments were performed on doubly charged ions and the resulting data were compared with those from theoretical calculations.

\section{Experimental}

All reagents and solvents were used as purchased without further purification.

\section{Glycation of HAS}

In vitro glycation of pure, defatted HSA was carried out with glucose, according to a published procedure [12]. Briefly, HSA (Sigma, St Louis, MO) [100 mg/mL $\left(1.5 \cdot 10^{-3} \mathrm{M}\right.$ ) in $0.01 \mathrm{M}$ phosphate buffer (Carlo Erba Reagenti, Rodano, Italy), $\mathrm{pH}$ 7.4, containing $5 \mathrm{mM}$ toluene (Carlo Erba Reagenti) as a bacteriostatic] was incubated with $0.5 \mathrm{M}$ D-glucose (Sigma, St Louis) at $37{ }^{\circ} \mathrm{C}$ for 28 days. After incubation, the HSA was separated from the solution by centrifugation through a Centricon-50 membrane (Millipore Corporation, Bedford, MA; MW cut-off 50,000 Da) at $5000 \times g$ for $1 \mathrm{~h}$, dialyzed extensively against distilled water (MW cutoff 50,000, Spectrum Laboratories) and then lyophilized. Unglycated HSA was incubated in the same conditions without the addition of glucose.

\section{Enzymatic Digestion with Trypsin}

One mg of glycated HSA was dissolved in $1.3 \mathrm{~mL}$ of 50 $\mathrm{mM} \mathrm{NH} \mathrm{NCO}_{3}$ buffer solution ( $\mathrm{pH}$ 8.3) (Carlo Erba Reagenti). After the addition of $15 \mu \mathrm{L}$ of a solution 45 $\mathrm{mM}$ of dithiothreitol (Fluka, St Louis, MO), the mixture was heated at $50{ }^{\circ} \mathrm{C}$ for $15 \mathrm{~min}$, then incubated with trypsin (Sigma) (200 $\mu \mathrm{L}$ of a solution $100 \mathrm{ng} / \mu \mathrm{L}$, substrate to enzyme ratio $=50: 1 \mathrm{w} / \mathrm{w}$ ) overnight at $37{ }^{\circ} \mathrm{C}$. The reaction was stopped with $80 \mu \mathrm{L}$ of $10 \%$ trifluoroacetic acid (TFA) (Fluka). Unglycated HSA was treated in the same manner. 

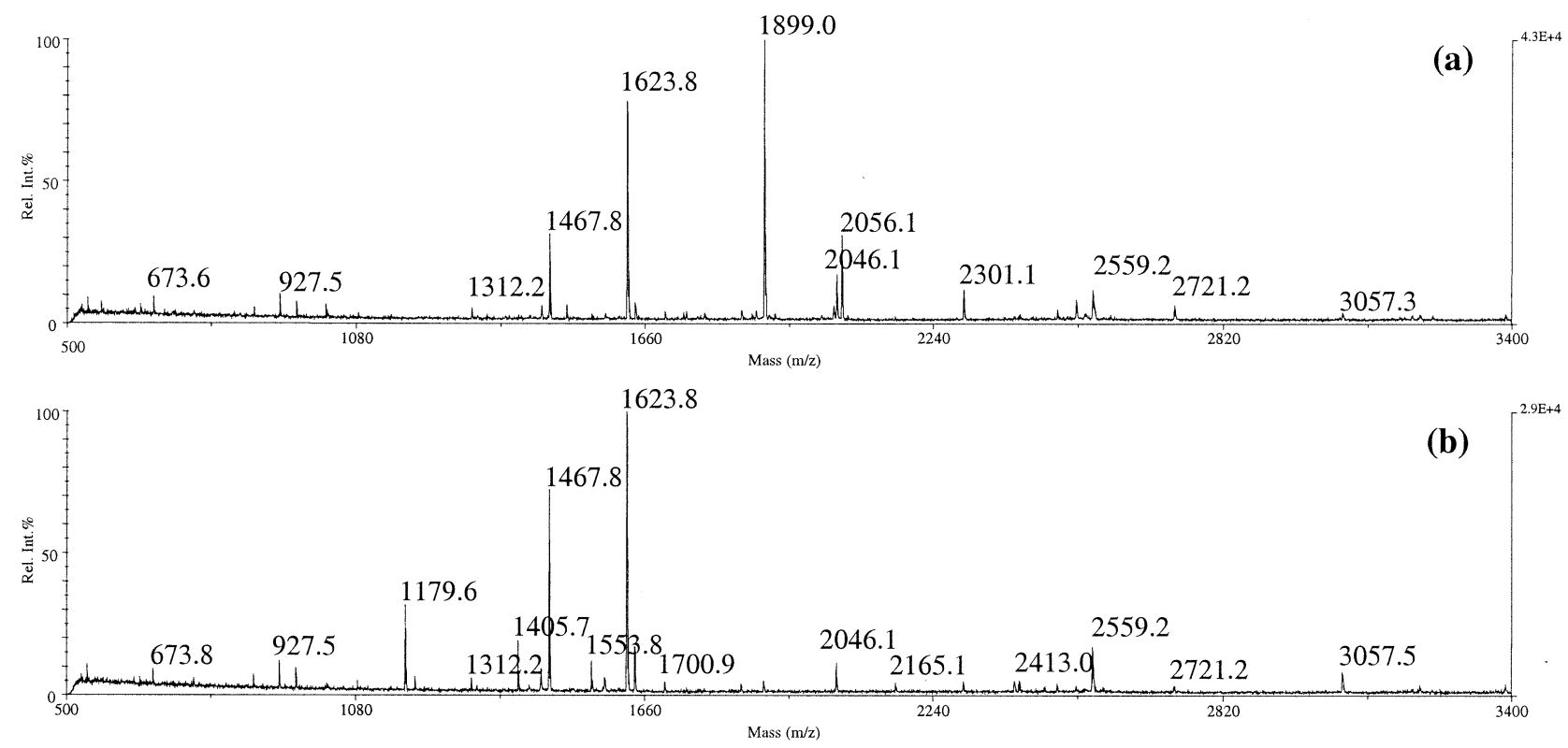

Figure 1. MALDI spectra of tryptic digests of (a) unglycated HSA and (b) glycated HSA.

\section{Enzymatic Digestion with Endoproteinase Lys-C}

$0.5 \mathrm{mg}$ of glycated HSA was dissolved in $50 \mu \mathrm{L}$ of 50 $\mathrm{mM} \mathrm{NH} \mathrm{NHCO}_{3}$ buffer solution ( $\mathrm{pH}$ 8.3). After the addition of $4.7 \mu \mathrm{L}$ of a solution $45 \mathrm{mM}$ of dithiothreitol, the mixture was heated at $50{ }^{\circ} \mathrm{C}$ for $15 \mathrm{~min}$, then incubated with Lys-C (Sigma) (50 $\mu \mathrm{L}$ of a solution 150 $\mathrm{ng} / \mu \mathrm{L}$, substrate to enzyme ratio $=66: 1 \mathrm{w} / \mathrm{w}$ ) overnight at $37{ }^{\circ} \mathrm{C}$. The reaction was stopped with $5 \mu \mathrm{L}$ of $10 \%$ TFA. Unglycated HSA was treated in the same manner.

\section{HPLC}

The tryptic digests were diluted 1:1 with 50\% acetonitrile solution containing $0.1 \% \mathrm{TFA}$, and $40 \mu \mathrm{L}$ of the sample solution was injected into a Jupiter C18 reversephase column, particle size $5 \mu \mathrm{m}, 250 \times 2 \mathrm{~mm}$ i.d. (Phenomenex, Torrance, CA). Solvent A consisted of water with $0.1 \%$ TFA and Solvent B of acetonitrile (Carlo Erba Reagenti) containing 0.1\% TFA. The gradient profile for Solvent B was as follows: 15\%, 1 min; $15-45 \%$ in $33 \mathrm{~min}$; 45\%, $5 \mathrm{~min}$; $45-95 \%$ in $10 \mathrm{~min}$; 95\%, $15 \mathrm{~min}$. The flow rate was $0.2 \mathrm{~mL} / \mathrm{min}$.

After elution from the column, the samples were analyzed by a diode array detector (1100 Series, Agilent Technologies, Palo Alto, CA) and then ionized by the ESI source of the mass spectrometer (see below). The Lys-C digests were diluted 1:10 with 50\% acetonitrile solution containing $0.1 \%$ TFA and analyzed in the same manner.

\section{ESI/MS}

ESI/MS was performed on a Agilent 1100 LC/MSD Trap (Agilent Technologies) operating in positive ion mode. Instrumental parameters were: Nebulizer pres- sure 40 psi, auxiliary gas flow $10 \mathrm{~mL} / \mathrm{min}$, temperature of auxiliary gas $325^{\circ} \mathrm{C}$, capillary voltage $4 \mathrm{kV}$, exit capillary voltage $50 \mathrm{~V}$, skimmer voltage $30 \mathrm{~V}$. MS and MS/MS analyses were performed for every sample, favoring fragmentation of doubly charged ions.

\section{MALDI/MS Measurements}

MALDI mass measurements were performed on a Voyager-DE PRO instrument (Applied Biosystems, Foster City, CA), operating in reflectron positive ion mode. Ions formed by a pulsed UV laser beam (nitrogen laser, $\lambda=337 \mathrm{~nm}$ ) were accelerated to $20 \mathrm{keV}$. Delayed extraction (DE) conditions were: Accelerating voltage $20 \mathrm{kV}$; grid voltage $76 \%$; guide wire $0.002 \%$; delay time 175 ns. $\alpha$-cyano-4-hydroxycinnamic acid (Sigma) was used as matrix $\left(10 \mathrm{mg} / \mathrm{mL}\right.$ in $\mathrm{H}_{2} \mathrm{O}$ /acetonitrile $1 / 1$ vol:vol). The digestion mixtures were diluted ten times with $0.1 \%$ trifluoroacetic acid aqueous solution, and 5 $\mathrm{mL}$ of this solution were added to the same volume of the matrix solution. About $1 \mathrm{~mL}$ of the resulting mixture was deposited on the stainless steel sample holder and allowed to dry before introduction into the mass spectrometer. Three independent measurements were taken for each sample. External mass calibration was applied using the Calibration Mixture 2 of Sequazyme Peptide Mass Standards Kit (Applied Biosystems), based on the monoisotopic values of $[\mathrm{M}+\mathrm{H}]^{+}$of Angiotensin I, ACTH (1-17 clip), ACTH (18-39 clip), ACTH (7-38 clip) and bovine insulin at $m / z$ 1296.68, 2093.09, 2465.20, 3657.93, and 5730.61 respectively.

\section{Computer-Molecular Modeling}

The entire HSA was built by computer-molecular modeling starting from the Protein Brookhaven Database 


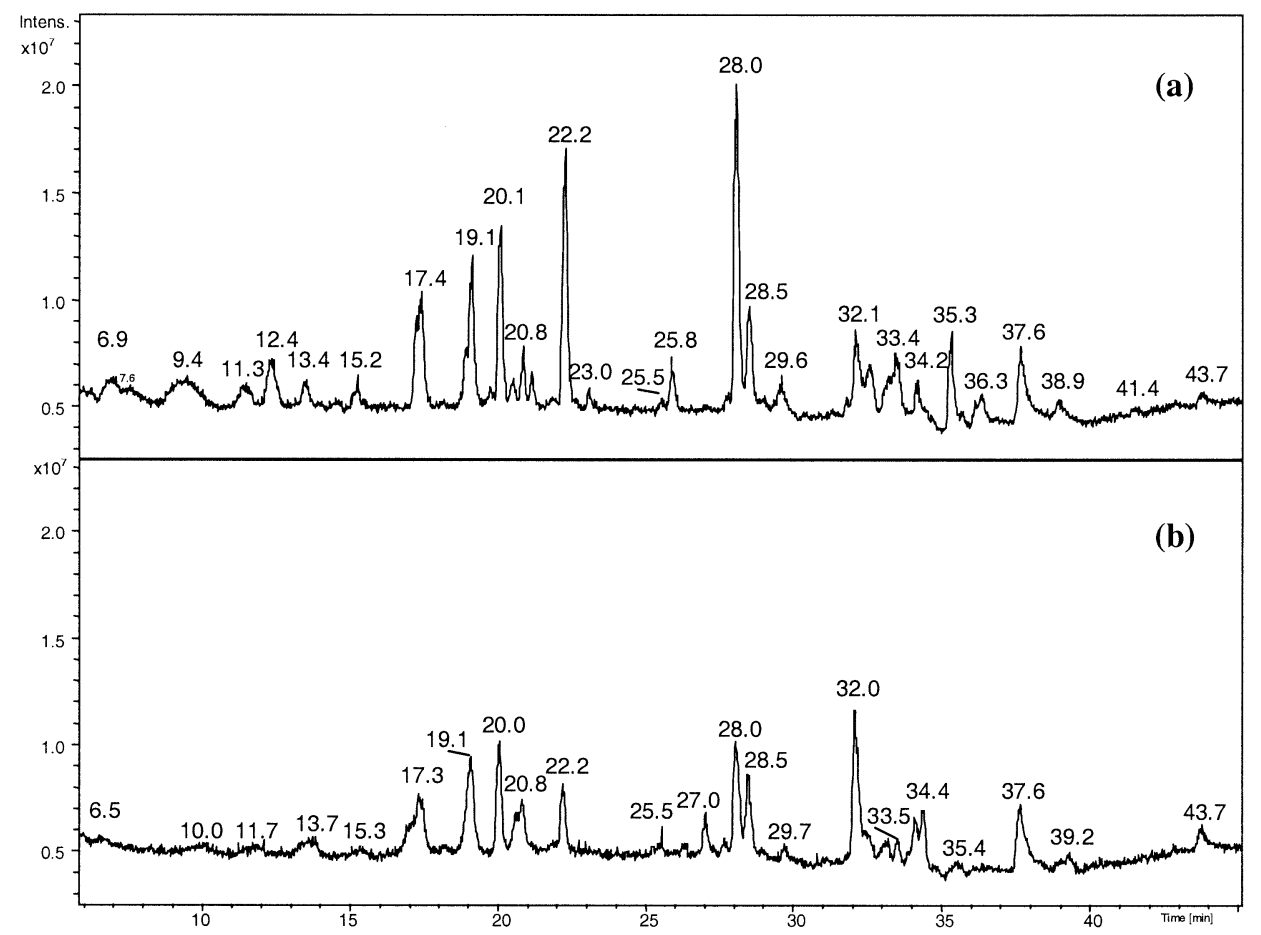

Figure 2. Total ion current (TIC) chromatograms of tryptic digests of (a) unglycated HSA and (b) glycated HSA.

file 1AO6.pdb (Brookhaven National Laboratory, Upton, NY).

All modeling was carried out using SYBYL and BIOPOLYMER modules of commercial software (Tripos, St. Louis, MO). The solvent accessible surfaces (SAS) of the amino acids making up the structure of HSA were calculated using the Xsight module of MSI software (MSI, San Diego, CA).

\section{Results and Discussion}

The present study is the logical evolution of previous studies devoted to identifying glycated peptides originating from enzymatic digestion of in vitro glycated HSA with proteinase K [11] and trypsin [12]. In principle, it would lead to the structural identification of AGE peptides whose presence, in further researches, will be verified in plasma samples of healthy, diabetic, and end-stage renal failure subjects.

We are well aware of the very different protein degradation mechanisms in in vitro experiments and in physiological conditions but, considering all the glycated peptides identified in the present and in the previous two investigations, we hope to obtain some interesting results, to be transposed in in vivo studies.

The general strategy employed in the present study may be summarized as follows: Unglycated and in vitro glycated HSA were digested by trypsin and Lys-C. Digestion was without any derivatization of the sulfhydryl groups, to remain as close as possible to the conditions present at a systemic level. The glycation level of the glycated protein was determined by MALDI measurements, yielding the total number of glucose molecules condensed on the protein. The digestion mixtures of both unglycated and glycated HSA were analyzed both by MALDI, to obtain their "fingerprints", and by LC with various detection systems: UV (214 and $280 \mathrm{~nm}$, effective for detection of peptides) and ESI/MS, performed by ion trap. The latter approach was applied to further $\mathrm{MS}^{\mathrm{n}}$ experiments. The experimental data were rationalized by comparison with databases and theoretical data from molecular modeling.

HSA was incubated with $0.5 \mathrm{M}$ glucose in sterile conditions for 28 days. The reason for choosing this high glucose concentration, quite far from physiopathological values $(20-50 \mathrm{mM})$ was to enhance the yield of glycation processes. The MALDI spectrum of the resulting sample showed a wide peak due to protonated molecules centered at $m / z$ 68921, whereas the spectrum of unglycated HSA detected $\mathrm{MH}^{+}$species at $\mathrm{m} / \mathrm{z} 66645$ (material available on request). Comparison of the two spectra showed that the glycated HSA sample is a mixture of proteins with different glycation levels, as proven by the broad shape of the peak; the mass value given above must be considered the mean. As the condensation of one glucose molecule leads to a mass increase of $162 \mathrm{Da}$, the mean $\mathrm{m} / \mathrm{z}$ value corresponds to proteins containing 14 glucose units. However, it must be taken into account that, considering the half-height peak width, the number of glucose molecules condensed on the protein ranges from 1 to 29 .

Glycated and unglycated HSA were digested by 
Table 1. Protonated ions of trypsin digestion products common to unglycated and glycated HSA, detected in both ESI and MALDI conditions

\begin{tabular}{|c|c|c|c|c|}
\hline $\begin{array}{l}\text { r.t } \\
(\min )\end{array}$ & {$[\mathrm{M}+\mathrm{H}]^{+} \mathrm{ESI}$} & Charge state & Sequence & {$[\mathrm{M}+\mathrm{H}]^{+} \mathrm{MALDI}^{*}$} \\
\hline 6.9 & $1518.7^{a}$ & $1+, 2+$ & $182-195$ & \\
\hline 7.1 & $1074.5^{\mathrm{a}}$ & $1+, 2+$ & $182-190$ & \\
\hline 8.9 & 880.4 & $1+, 2+$ & $226-233$ & \\
\hline 9.6 & 875.3 & $1+, 2+$ & $219-225$ & 875.3 \\
\hline 11.5 & 1022.4 & $1+, 2+$ & $476-484$ & 1022.6 \\
\hline 11.7 & $1296.4^{a}$ & $2+$ & $349-359$ & \\
\hline 12.2 & 789.4 & $1+, 2+$ & $234-240$ & \\
\hline 13.4 & 1318.5 & $1+, 2+$ & $82-93$ & \\
\hline 13.5 & 673.3 & $1+, 2+$ & $213-218$ & 673.6 \\
\hline 15.3 & 1189.6 & $1+, 2+$ & $277-386$ & \\
\hline 17.2 & 1226.7 & $1+, 2+$ & $11-20$ & \\
\hline 17.4 & 1430.8 & $1+, 2+$ & $275-286$ & \\
\hline 18.5 & 1252.4 & $2+$ & $223-233$ & \\
\hline 18.7 & 1055.5 & $1+, 2+$ & $137-144$ & \\
\hline 18.9 & 927.5 & $1+, 2+$ & $138-144$ & 927.5 \\
\hline 19.1 & 1149.9 & $1+, 2+$ & $42-51$ & 1149.7 \\
\hline 19.4 & $1737.6^{\mathrm{a}}$ & $2+$ & $219-233$ & \\
\hline 19.7 & $1016.9^{a}$ & $1+$ & $65-73$ & \\
\hline 20.0 & 1640.1 & $1+, 2+$ & $414-428$ & \\
\hline 20.5 & 1019.4 & $1+, 2+$ & $210-218$ & 1019.7 \\
\hline 20.8 & 960.4 & $1+, 2+$ & $403-410$ & 960.8 \\
\hline 21.1 & 1128.7 & $1+, 2+$ & $525-534$ & \\
\hline 21.2 & 3244.9 & $3+$ & $546-574$ & \\
\hline \multirow[t]{2}{*}{21.9} & 2381.2 & $2+, 3+$ & $198-218$ & \\
\hline & 1001.6 & $1+, 2+$ & $526-534$ & \\
\hline 22.2 & 1013.9 & $\begin{array}{l}1+, 2+ \\
+\mathrm{Na}\end{array}$ & $575-585$ & \\
\hline 23.0 & 2413.8 & $2+, 3+$ & $241-262$ & 2414.0 \\
\hline 24.6 & 1854.1 & $2+$ & $485-500$ & 1853.3 \\
\hline 25.5 & 3184.6 & $2+, 3+$ & $234-262$ & \\
\hline \multirow{2}{*}{25.9} & 1600.6 & $1+, 2+$ & $390-402$ & \\
\hline & 983.7 & $1+$ & $352-359$ & \\
\hline 27.7 & $3239.4^{a}$ & $2+, 3+$ & $52-81$ & 3239.0 \\
\hline 27.9 & 2488.8 & $2+, 3+$ & $501-521$ & 2488.0 \\
\hline \multirow{2}{*}{28.0} & 2045.2 & $2+, 3+$ & $373-389$ & 2046.1 \\
\hline & 1342.8 & $1+, 2+$ & $546-557$ & \\
\hline 28.5 & 1468.0 & $1+, 2+$ & $337-348$ & $1467-8$ \\
\hline 29.0 & 1311.7 & $1+, 2+$ & $338-348$ & 1312.2 \\
\hline 29.5 & 2722.4 & $2+, 3+$ & $115-137$ & 2721.2 \\
\hline 29.8 & 2935.0 & $2+, 3+$ & $137-159$ & \\
\hline 31.8 & 2543.2 & $2+, 3+$ & $390-410$ & 2543.0 \\
\hline 32.1 & 3543.2 & $2+, 3+$ & $445-475$ & 3542.0 \\
\hline 32.2 & 2918.4 & $2+, 3+$ & $287-313$ & \\
\hline 32.4 & 1651.7 & $1+, 2+$ & $226-240$ & \\
\hline 32.5 & 3362.6 & $3+$ & $287-317$ & \\
\hline 32.6 & 3215.4 & $2+, 3+$ & $445-472$ & 3213.0 \\
\hline 33.2 & 2559.2 & $2+, 3+$ & $445-466$ & 2559.2 \\
\hline \multirow{2}{*}{33.5} & 3058.4 & $2+, 3+$ & $446-472$ & 3057.3 \\
\hline & 2055.6 & $2+, 3+$ & $145-160$ & 2056.1 \\
\hline 33.9 & 1639.7 & $1+, 2+$ & 324-336 1Met-ox & 1639.5 \\
\hline 34.1 & $1898.9^{a}$ & $1+, 2+$ & $145-159$ & 1899.0 \\
\hline 34.2 & 2403.0 & $2+$ & $446-466$ & \\
\hline 34.4 & 746.4 & $1+$ & $21-27$ & \\
\hline 35.3 & 1898.9 & $1+, 2+$ & $146-160$ & 1899.0 \\
\hline 36.1 & 1742.8 & $1+, 2+$ & $146-159$ & 1742.5 \\
\hline 36.3 & 2301.0 & $2+, 3+$ & $318-336$ & 2301.2 \\
\hline 37.6 & 1623.9 & $1+, 2+$ & $324-336$ & 1623.8 \\
\hline
\end{tabular}

apeptides present only in the digestion products of unglycated HSA.

*Further ionic species were detected in MALDI conditions only: 1083.8 (sequence 138-145), 1502.6 (sequence 210-222), 1699.5 (sequence 429-444),

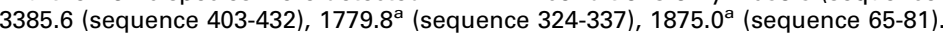


Table 2. Protonated ions of trypsin digestion products presented only in glycated HSA detected in ESI spectra and compared with MALDI data

\begin{tabular}{|c|c|c|c|c|c|}
\hline r.t. (min) & {$[\mathrm{M}+\mathrm{H}]^{+} \mathrm{ESI}$} & Charge state & {$[\mathrm{M}+\mathrm{H}]^{+} \mathrm{MALDI}$} & $\begin{array}{c}\text { Sequence } \\
(+ \text { mass increase })\end{array}$ & Modified amminoacid \\
\hline 11.5 & 1458.7 & $1+, 2+$ & & $349-359(+162)$ & ${ }^{351} \mathrm{~K}$ \\
\hline 13.5 & 1512.4 & $2+$ & & & \\
\hline 17.0 & 1592.7 & $1+, 2+$ & & $275-286(+162)$ & ${ }^{276} \mathrm{~K}$ \\
\hline 19.0 & 1179.5 & $1+, 2+$ & 1179 & & \\
\hline 20.6 & 1290.7 & $1+, 2+$ & & $525-534(+162)$ & ${ }^{525} \mathrm{~K}$ \\
\hline 21.6 & 2542.6 & $2+, 3+$ & & $198-218(+162)$ & ${ }^{199} \mathrm{~K}$ or ${ }^{205} \mathrm{~K}$ or ${ }^{209} \mathrm{R}$ or ${ }^{212} \mathrm{~K}$ \\
\hline 24.3 & 3940.0 & $3+$ & & $440-472(+162)$ & ${ }^{444} \mathrm{~K}$ or ${ }^{445} \mathrm{R}$ or ${ }^{466} \mathrm{~K}$ \\
\hline 25.2 & 1578.6 & $1+, 2+$ & 1579.0 & $187-199(+162)$ & ${ }^{190} \mathrm{~K}$ or ${ }^{195} \mathrm{~K}$ or ${ }^{197} \mathrm{R}$ \\
\hline 25.5 & 1056.5 & $1+, 2+$ & & & \\
\hline 26.3 & 894.4 & $1+, 2+$ & & & \\
\hline 27.0 & 1198.7 & $1+, 2+$ & 1198.6 & $137-144(+144)$ & ${ }^{137} \mathrm{~K}$ \\
\hline 27.6 & 2207.6 & $2+, 3+$ & & $373-389(+162)$ & ${ }^{378} \mathrm{~K}$ \\
\hline 28.2 & 738.3 & $1+, 2+$ & & & \\
\hline 29.7 & 1405.8 & $1+, 2+$ & 1405.7 & & \\
\hline 31.6 & 3523.9 & $3+$ & & $287-317(+162)$ & ${ }^{313} \mathrm{~K}$ \\
\hline 32.1 & 1812.9 & $1+, 2+$ & & $226-240(+162)$ & ${ }^{233} \mathrm{~K}$ \\
\hline 32.4 & 2003.0 & $2+$ & & $542-557(+162)$ & ${ }^{545} \mathrm{~K}$ \\
\hline \multirow[t]{2}{*}{33.1} & 2303.8 & $2+$ & & $539-557(+162)$ & ${ }^{541} \mathrm{~K}$ or ${ }^{545} \mathrm{~K}$ \\
\hline & 1396.5 & $1+, 2+$ & & $223-233(+144)$ & ${ }^{225} \mathrm{~K}$ \\
\hline \multirow[t]{2}{*}{35.5} & 2462.8 & $2+, 3+$ & 3462.2 & $318-336(+162)$ & ${ }^{323} \mathrm{~K}$ \\
\hline & 2185.8 & $2+, 3+$ & & $223-240(+162)$ & ${ }^{225} \mathrm{~K}$ \\
\hline 39.3 & 2164.2 & $2+$ & 2165.1 & & \\
\hline
\end{tabular}

trypsin and Lys-C (see procedure described in Experimental section). In view of the complexity and high number of results, the data relating to the two types of enzymatic digestion are described and discussed separately, and compared in the Conclusion section.

\section{Digestion by Trypsin}

The MALDI spectra of the tryptic digests of unglycated and glycated HSA are shown in Figure 1, comparison of which clearly reveals differences between the two. At first sight, the most evident result is the complete disappearance of ionic species at $m / z 1899.0$ (which, in the case of the sample from unglycated HSA, represents the most abundant one) and 2056.1 in the glycated HSA digest. Some other peptides remain present in both mixtures, e.g., those at $\mathrm{m} / \mathrm{z} 1467.8$ and 1623.8. However, the MALDI spectra of Figure 1b show few new species, generally of low abundance, in the digestion mixture from glycated HSA. This is the case of the ions at $\mathrm{m} / \mathrm{z}$ 1179.6, 1405.7, 1700.9, 2165.1, and 2413.0.

These results may appear at first sight disappointing, since a larger difference would have been expected. However, they are very similar to those obtained in previous studies which indicate a lower proclivity to- ward digestion for glycated protein. This aspect was also considered, not only in in vitro experiments but also cited as the rationale for some results obtained in physiological conditions. Both works by Schnider and Kohn [14] and Vlassara et al. [2] relate this aspect with the solubility of collagen from human skin, tracheal cartilage and dura mater and, more generally, with its implications for diabetes and aging.

The same tryptic digests were analyzed by LC. In the case of the unglycated HSA digest, UV detection at 214 $\mathrm{nm}$ (material available on request) revealed its high complexity: Some peaks detected here disappeared in the sample from glycated HSA and in the latter case, new species became detectable. Similar results were obtained with UV detection at $280 \mathrm{~nm}$ (material available on request), further confirming that glycated HSA is less prone to enzymatic digestion. Passing to LC/ ESI/MS experiments, the total ion chromatograms (Figure 2) confirm the UV data (cfr. chromatograms of digestion products from unglycated HSA, Figure 2a, with those from glycated HSA, Figure 2b). These chromatograms are the starting point of an extensive investigation devoted to identifying the various peptides produced by enzymatic digestion.

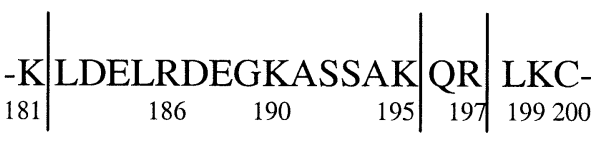

unglycated HSA

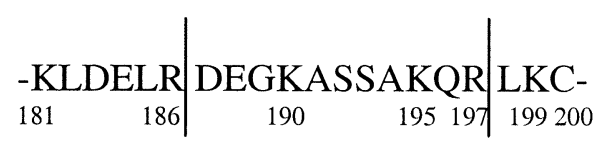

glycated HSA 

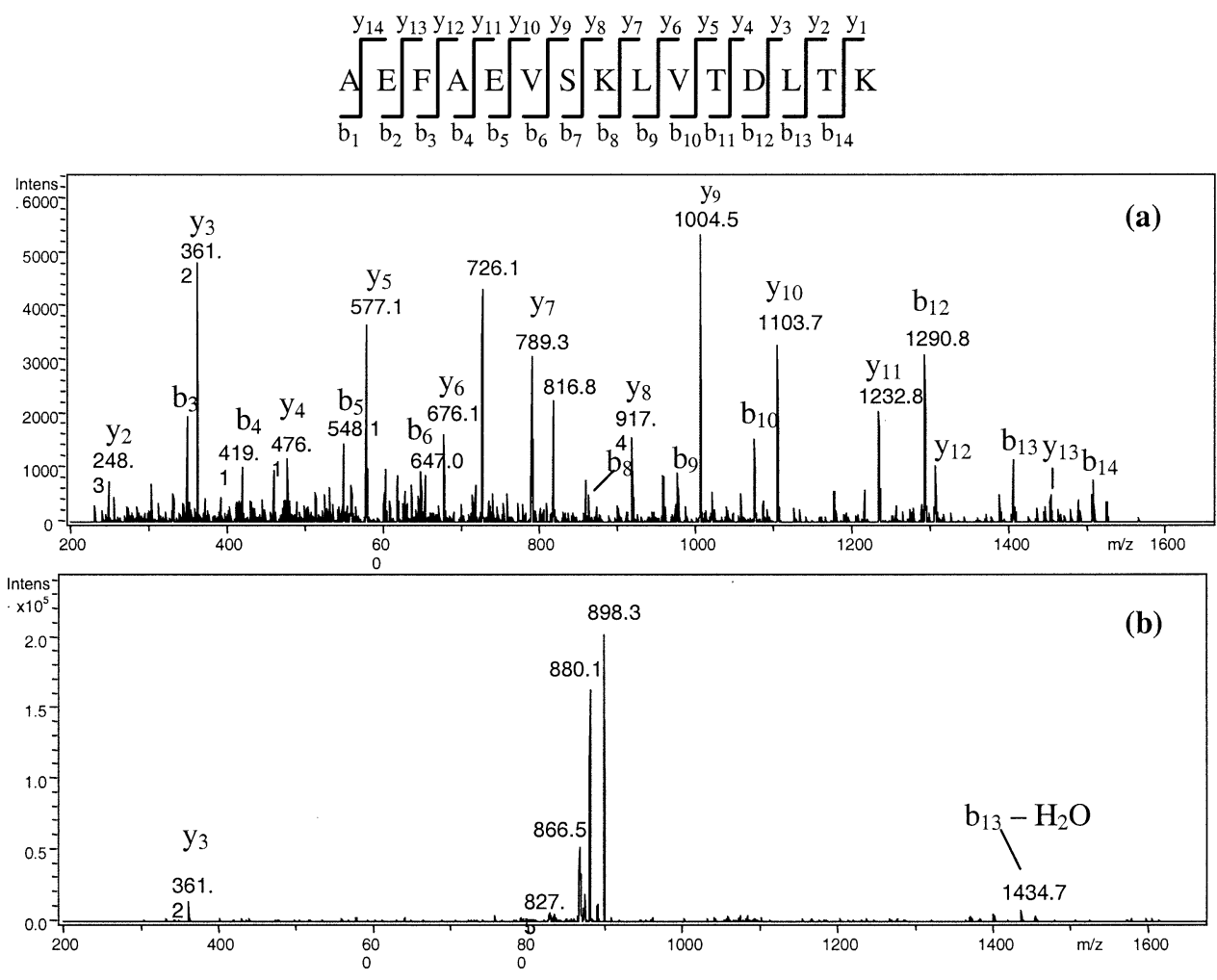

Figure 3. MS/MS spectrum of doubly charged ions corresponding to sequence 226-240 (a) unglycated $(\mathrm{m} / \mathrm{z} 826.0)$ and $(\mathbf{b})$ containing a glucose molecule condensed on ${ }^{233} \mathrm{~K}(\mathrm{~m} / \mathrm{z}$ 907.3).

The mass spectrometric data obtained for the two tryptic digests are listed in Tables 1 and 2. The ESI and MALDI data for the digest of unglycated HSA are shown in Table 1. The sequences of Column 4 were obtained by comparing the mass values of the various peptides with those calculated by the protein digestion tool MS-Digest (ProteinProspector version 4.0.5). It must be emphasized that the comparison of LC/ ESI/MS and MALDI data (Table 1) indicates that the former approach is the more effective, since only 27 of the 56 peptides detected by LC/ESI/MS also occur in the MALDI spectra. However, in MALDI conditions,
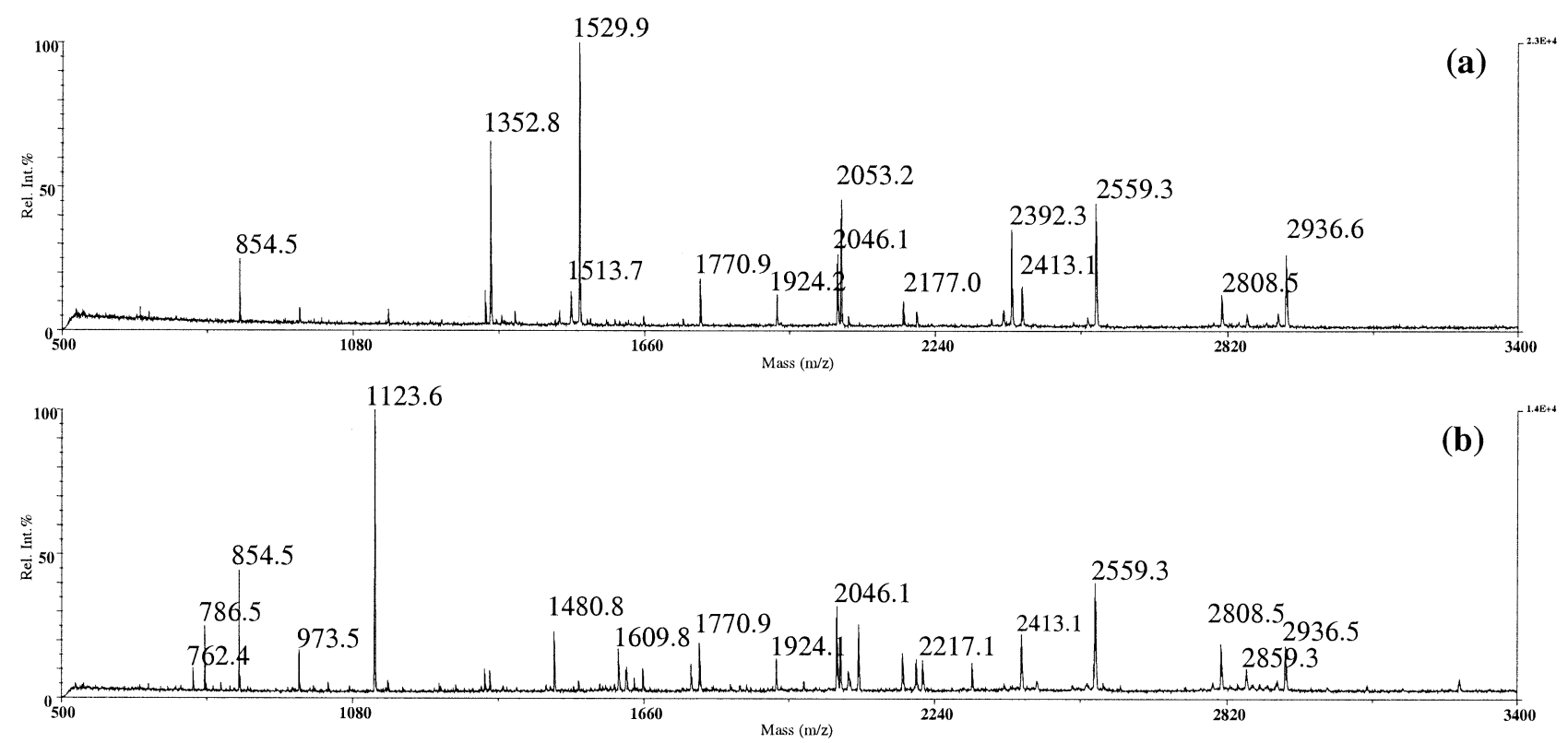

Figure 4. MALDI mass spectra of Lys-C digests of: (a) Unglycated HSA and (b) glycated HSA. 


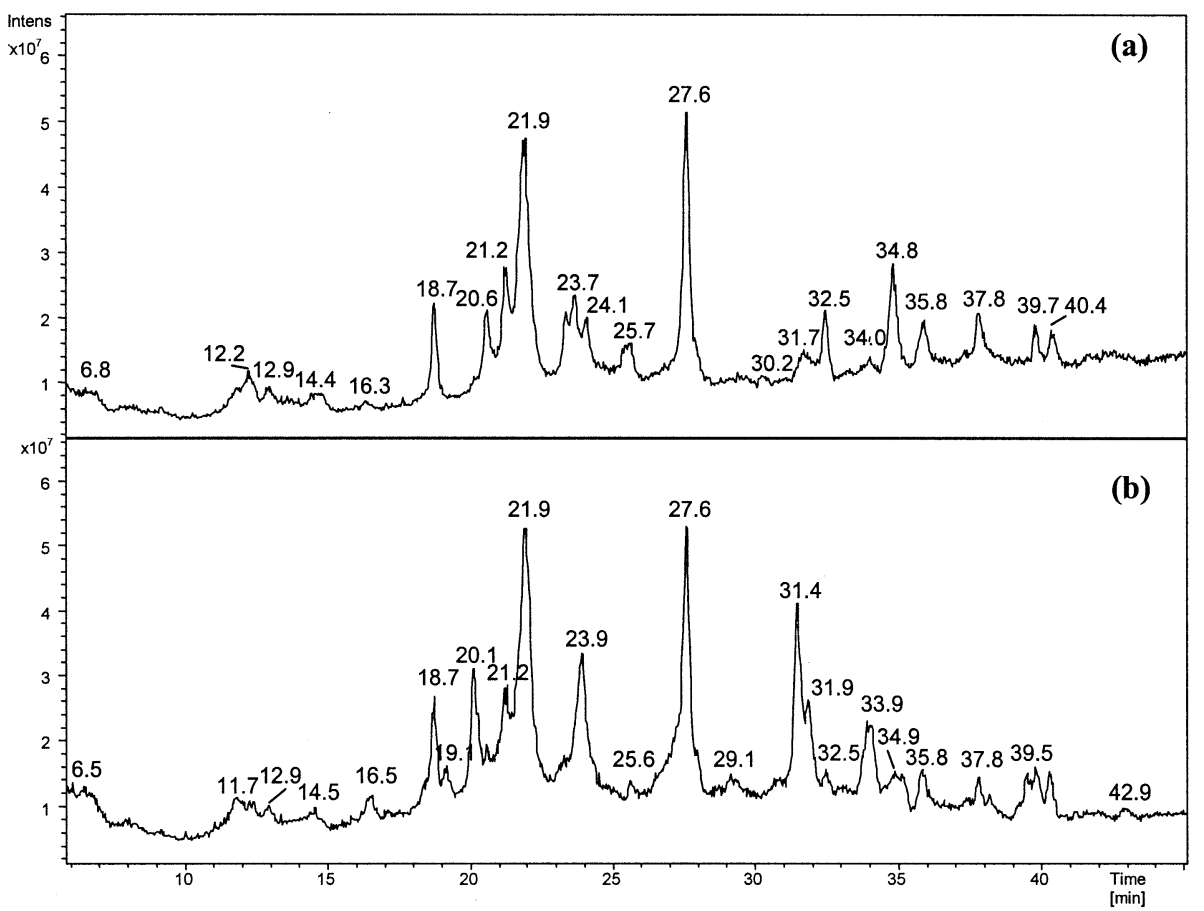

Figure 5. Total ion current (TIC) chromatograms of Lys-C digests of: (a) Unglycated and (b) glycated HSA.

other peptides, undetectable in ESI conditions, were identified and are reported in the note to Table 1. For an idea on the validity of these results, it must be stressed that the identified peptides cover $78 \%$ of the whole protein.

Data pertaining to the tryptic digest of glycated HSA show the presence of most of the peptides detected in the case of the unglycated HSA digest, although in lower abundance. However, as expected, a series of new peptides (some glycated, some others, as discussed below, originating from a different enzymatic action) occur; for easier discussion of the data, only peptides characteristic of glycated HSA are listed in Table 2. These possibly glycated peptides show mass values ranging from 738.3 to $3940.0 \mathrm{Da}$. In principle, they originate from portions of HSA in which glucose molecule(s) have condensed, with and without further dehydration processes. For example, the peptide detected at a retention time of $27.0 \mathrm{~min}$ shows a mass value of 1198.7, corresponding to the sequence 137-144, in which the dehydrated glucose molecule has condensed on ${ }^{137} \mathrm{~K}$. Interestingly, the unglycated peptide with the same sequence is present in the digestion mixture of unglycated HSA at $m / z 1055.5$ (r.t. $=18.7$ $\min )$.

However, it should be emphasized that profound changes occur in enzyme action, as evidenced by the data of Table 2. First of all, some enzymatic cleavages, never observed in the case of unglycated HSA, become operative, proving that glycation strongly modifies enzyme action. For example, the peak eluting at $17 \mathrm{~min}$ is due to the glycated peptide with sequence 275-286; the same sequence, obviously not glycated, is completely absent in the case of unglycated HSA. A further example is shown by the data relating to the sequence of in Scheme 1. The portion 181-200 of unglycated HSA undergoes different cleavage when glycated. Thus, the left side of Scheme $\mathbf{1}$ shows that the unglycated sequence is enzymatically cleaved at ${ }^{181} \mathrm{~K},{ }^{195} \mathrm{~K}$, and ${ }^{197} \mathrm{R}$, whereas in the case of glycation (in either ${ }^{190} \mathrm{~K}$ or ${ }^{195} \mathrm{~K}$ ), cleavages occur at ${ }^{186} R$ and ${ }^{197} R$.

As in the example above, assignment of the glycation site cannot always be made on the basis of the peptide mass value when it contains differing $\mathrm{K}$ residues. As shown in Table 2, for some of these peptides no sequences could be assigned.

As for the tryptic digest of unglycated HSA, a lower number of characteristic peptides originating from the tryptic digestion of glycated HSA were been detected by MALDI/MS (Table 2 ).

The sequence data, first obtained by comparison with databases, were investigated by MS/MS experiments on doubly charged ions. In the case of peptides from unglycated HSA, spectra analogous to that shown in Figure $3 a$ for the ion at $\mathrm{m} / \mathrm{z} 826.0$ (corresponding to the sequence 226-240) were obtained, and the ions of the $\mathrm{y}$ and $\mathrm{b}$ series are clearly evidenced.

In the case of peptides containing a glucose moiety, completely different behavior was observed, as shown in the MS/MS spectrum of the doubly charged ion at $m / z$ 907.3, corresponding to the sequence 226-240, with a glucose molecule condensed on ${ }^{233} \mathrm{~K}$ (see Figure $3 b$ ). In this case, only a highly favored water loss is observed, and ions due to the $y$ and $b$ series are practically 
Table 3. Protonated ions of Lys-C digestion products common to unglycated and glycated HSA, detected in both ESI and MALDI conditions

\begin{tabular}{|c|c|c|c|c|}
\hline r.t. & {$[\mathrm{M}+\mathrm{H}]^{+} \mathrm{ESI}$} & Charge state & Sequence & {$[\mathrm{M}+\mathrm{H}]^{+} \mathrm{MALDI}$} \\
\hline 6.8 & 973.7 & $1+, 2+$ & $5-12$ & 973.5 \\
\hline $6.0-6.8$ & 1379.7 & $1+, 2+$ & $360-372$ & \\
\hline 8.3 & 1386.7 & $1+, 2+$ & $263-274$ & \\
\hline 9.2 & 880.6 & $1+, 2+$ & $226-233$ & \\
\hline 12.2 & 789.7 & $1+, 2+$ & $234-240$ & \\
\hline 12.4 & 951.7 & $1+, 2+$ & $13-20$ & \\
\hline 12.9 & 854.7 & $1+$ & 206-212 & 854.5 \\
\hline 13.6 & 1255.6 & $1+, 2+$ & $163-174$ & 1255.5 \\
\hline 14.8 & 1189.9 & $1+, 2+$ & $277-286$ & \\
\hline 16.3 & 1627.9 & $1+, 2+$ & $263-276$ & 1627.8 \\
\hline 18.7 & 1149.8 & $1+, 2+$ & $42-51$ & 1149.6 \\
\hline 20.6 & 1128.9 & $1+, 2+$ & $525-534$ & \\
\hline 21.2 & 1017.9 & $1+, 2+$ & $65-73$ & 1017.5 \\
\hline 21.5 & 2414.0 & $2+, 3+$ & $241-262$ & 2413.1 \\
\hline \multirow{2}{*}{21.8} & 1353.0 & $1+, 2+$ & $403-413$ & 1352.8 \\
\hline & 1001.0 & $1+, 2+$ & $526-534$ & \\
\hline 21.9 & 1013.9 & $1+, 2+,+\mathrm{Na}$ & $575-585$ & \\
\hline 22.2 & 1141.9 & $1+, 2+$ & $565-574$ & \\
\hline 23.4 & 1530.0 & $1+, 2+, 3+$ & $213-225$ & 1529.9 \\
\hline 23.7 & 2053.4 & $2+, 3+$ & $414-432$ & 2053.2 \\
\hline 24.0 & 1771.0 & $1+, 2+$ & $175-190$ & 1770.9 \\
\hline 24.1 & 1924.1 & $1+, 2+$ & $415-432$ & \\
\hline 25.2 & 2858.6 & $2+, 3+$ & $501-524$ & 2859.3 \\
\hline 25.3 & $2393.8^{a}$ & $2+, 3+$ & $213-233$ & 2392.3 \\
\hline \multirow{2}{*}{25.6} & 1600.9 & $1+, 2+$ & $390-402$ & 1600.7 \\
\hline & 983.8 & $1+$ & $352-359$ & \\
\hline 26.8 & 2176.4 & $2+, 3+$ & $542-560$ & 2177.0 \\
\hline 27.5 & 2046.6 & $2+, 3+$ & $373-389$ & 2046.1 \\
\hline 27.6 & 1342.9 & $1+, 2+$ & $546-557$ & 1342.6 \\
\hline 28.0 & 2203.0 & $2+, 3+$ & $501-519$ & 2203.0 \\
\hline 31.7 & 2918.8 & $2+, 3+$ & $287-313$ & 2919.3 \\
\hline 32.4 & 2559.8 & $2+, 3+$ & $445-466$ & 2559.3 \\
\hline 34.0 & 746.5 & $1+$ & $21-27$ & \\
\hline 34.8 & 2937.0 & $2+, 3+$ & 137-159 & 2935.6 \\
\hline 35.8 & 2809.8 & $2+, 3+$ & $138-159$ & 2808.5 \\
\hline 37.4 & 4064.2 & $3+, 4+$ & $318-351$ & \\
\hline
\end{tabular}

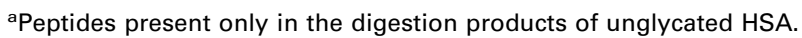

undetectable. However, in some cases, the poorly abundant $\mathrm{y}$ and $\mathrm{b}$ series ions identified the glycation sites (e.g., ${ }^{351} \mathrm{~K},{ }^{525} \mathrm{~K},{ }^{137} \mathrm{~K},{ }^{378} \mathrm{~K},{ }^{313} \mathrm{~K},{ }^{233} \mathrm{~K},{ }^{545} \mathrm{~K},{ }^{225} \mathrm{~K}$, and ${ }^{323} \mathrm{~K}$; see Table 2). In other cases, identification of glycation site(s) was impossible, due to the complete lack of any specific $y$ and $b$ ions in the MS/MS spectra of the related doubly charged ions (e.g., peptides at $\mathrm{m} / \mathrm{z}$ 1578.6, 2303.8, 2542.6, and 3940.0; see Table 2). $\mathrm{MS}^{3}$ spectra from collisionally generated $\left[\mathrm{M}-\mathrm{H}_{2} \mathrm{O}\right]^{2+}$ species show very few product ions still related to the glucose moiety.

This behavior may be ascribed to the collision conditions in the ion trap experiments: the low, step-bystep energy deposition, typical of the device [15], greatly favors low critical energy decomposition channels, and the water loss, being a process requiring $\mathrm{H}$ rearrangement, is certainly more energetically favored than single bond cleavage.

However, what at first sight may be viewed as a negative aspect is really a highly efficient diagnostic tool in identifying glucose-containing peptides among the digestion products of glycated HSA. This point is more easily evaluated by the following general consideration: Digestion of glycated HSA leads to some peptides which are also produced in the case of unglycated protein and to new peptides, some of them glucosecontaining and some not, due to different enzyme activity. In the case of the present study, devoted to the structure identification of possible AGE-peptides, discrimination between the two sets of compounds is essential, and MS/MS experiments are highly effective in this respect.

\section{Digestion by Lys-C}

Lys-C is a serine protease and, at $\mathrm{pH} 8.3$, specifically cleaves peptide bonds C-terminally at lysine [16]. After the action of this enzyme, unglycated and glycated HSA give the MALDI mass spectra of Figure $4 a$ and $b$ respectively. As in the case of trypsin digestion, some of the species originating from the unglycated protein can no longer be detected in the spectrum of digestion 
Table 4. Protonated ions of Lys-C digestion products present only in glycated HSA, detected in ESI spectra and compared with MALDI data

\begin{tabular}{|c|c|c|c|c|c|}
\hline $\begin{array}{l}\text { r.t. } \\
(\mathrm{min})\end{array}$ & $\begin{array}{c}{[\mathrm{M}+\mathrm{H}]^{+}} \\
\mathrm{ESI}\end{array}$ & Charge state & $\begin{array}{c}{[\mathrm{M}+\mathrm{H}]^{+}} \\
\text {MALDI }\end{array}$ & $\begin{array}{c}\text { Sequence } \\
(+ \text { mass increase })\end{array}$ & Modified amminoacid \\
\hline 4.9 & 970.9 & $1+$ & & $535-541(+162)$ & ${ }^{536} \mathrm{~K}$ \\
\hline 6.1 & 762.7 & $1+, 2+$ & 762.4 & & \\
\hline 15.8 & 1866.4 & $2+$ & 1865.8 & $160-174(+162)$ & ${ }^{162} \mathrm{~K}$ \\
\hline 16.4 & 1594.2 & $2+$ & 1593.7 & $275-286(+162)$ & $276 K$ \\
\hline 18.5 & 1069.9 & $1+, 2+$ & & & \\
\hline \multirow{2}{*}{19.1} & 1626.0 & $1+, 2+$ & 1625.9 & $403-414(+144)$ & ${ }^{413} \mathrm{~K}$ \\
\hline & 1754.2 & $2+, 3+$ & 1754.0 & 414-429 & Not glycated (cleavage at ${ }^{429} \mathrm{~N}$ ) \\
\hline 19.6 & 2107.8 & $2+, 3+$ & & & \\
\hline 20.1 & 1291.0 & $1+, 2+$ & & $525-534(+162)$ & ${ }^{525} \mathrm{~K}$ \\
\hline 20.5 & 2676.6 & $2+, 3+$ & & $42-64(+162)$ & ${ }^{51} \mathrm{~K}$ \\
\hline 20.9 & 2544.4 & $2+, 3+$ & & $198-218(+162)$ & ${ }^{199} \mathrm{~K}$ or ${ }^{205} \mathrm{~K}$ or ${ }^{209} \mathrm{~K}$ or ${ }^{212} \mathrm{~K}$ \\
\hline 23.0 & 2378.8 & $2+, 3+$ & 2378.2 & $175-195(+162)$ & ${ }^{181} \mathrm{~K}$ or ${ }^{190} \mathrm{~K}$ \\
\hline 23.8 & 786.8 & $1+, 2+$ & 787.5 & & Not glycated \\
\hline 23.9 & 1124.0 & $1+, 2+$ & 1123.6 & $403-411$ & Not glycated (cleavage at ${ }^{411} \mathrm{Y}$ ) \\
\hline 24.3 & 804.7 & $1+$ & & & \\
\hline 24.6 & 2089.0 & $2+, 3+$ & 2088.0 & & \\
\hline 24.9 & 1578.1 & $1+, 2+$ & 1577.7 & $275-286(+144)$ & \\
\hline 26.9 & 3021.0 & $2+, 3+$ & 3020.4 & & \\
\hline 27.4 & 2208.4 & $2+$ & & $373-389(+162)$ & ${ }^{378} \mathrm{~K}$ \\
\hline 27.6 & 738.7 & $1+, 2+$ & & & \\
\hline 28.2 & 2558.4 & $2+, 3+$ & 2558.3 & $241-262(+144)$ & ${ }^{257} \mathrm{R}$ or ${ }^{262} \mathrm{~K}$ \\
\hline 30.7 & 3284.0 & $2+, 3+$ & 3284.6 & $440-466(+162)$ & ${ }^{444} \mathrm{~K}$ \\
\hline 31.4 & 2200.2 & $2+$ & & & \\
\hline 31.6 & 1813.2 & $1+, 2+, 3+$ & & $226-240(+162)$ & ${ }^{233} \mathrm{~K}$ \\
\hline 31.7 & 2315.0 & $2+, 3+$ & 2314.2 & & \\
\hline 31.9 & 2004.4 & $2+$ & & $542-557(+162) 545 K$ & \\
\hline 33.8 & 1285.0 & $1+, 2+$ & 1284.7 & $565-574(+144)$ & ${ }^{573} \mathrm{~K}$ \\
\hline 34.5 & 3099.0 & $2+, 3+$ & & & \\
\hline 35.1 & 1346.1 & $1+, 2+$ & & $149-159$ & Not glycated (cleavage at ${ }^{148} \mathrm{Y}$ ) \\
\hline 35.5 & 1834.8 & $2+$ & 1832.9 & & \\
\hline 37.0 & 3169.6 & $2+, 3+$ & 3170.8 & & \\
\hline 39.1 & 1572.0 & $1+, 2+$ & 1571.9 & & \\
\hline \multirow{2}{*}{39.4} & 2078.0 & $2+$ & & & \\
\hline & 2596.6 & $2+, 3+$ & & & \\
\hline 39.5 & 1237.1 & $1+, 2+$ & & & \\
\hline 41.1 & 3728.2 & $3+, 4+$ & & & \\
\hline 41.6 & 4514.5 & $3+, 4+, 5+$ & & $324-359(+162)$ & ${ }^{351} \mathrm{~K}$ \\
\hline 42.7 & 3080.0 & $2+$ & & & \\
\hline
\end{tabular}

products of glycated HSA. In the latter case, new ions become detectable, among which some AGE peptides must necessarily be present. These differences are further evidenced by the LC run of the two digestion mixtures. UV detection (214 nm; material available on request) highlighted a large number of glycated peptides in the retention time range $36-43 \mathrm{~min}$, leading to a broad chromatographic peak. These species must be highly absorbing compounds, since the same behavior is not observed in the LC/MS run (Figure 5b), in which components differing from those in the unglycated HSA digestion mixture are present, but with comparable abundances.

Analysis of the LC/ESI/MS data with the same methods employed in the case of trypsin digestion are reported in Tables 3 and 4 . Table 3 shows that most of the peptides originating from Lys-C digestion of unglycated HSA are species already detected in the tryptic digest (see Table 1). In this case, the identified peptides cover $70 \%$ of the whole protein. Only a few of them are specifically produced by Lys-C. The HSA digestion data obtained from trypsin and Lys-C are compared in Figure 6: The green color code represents the protein portion whose related peptides were identified with both enzymes; blue indicates peptides only identified in digestion by Lys-C; yellow shows digestion products for trypsin only.

The enzyme activity of Lys-C on glycated HSA is very different from that observed for trypsin. As shown in Table 4, in which only peptides specific for digestion of glycated HSA are listed, a high number of peptides are generated (54; in the case of trypsin digestion, only 22 were detected). At first sight, these results are surprising; the higher specificity of Lys-C (which cleaves at $K$ residues) versus trypsin (which cleaves at both $\mathrm{K}$ and $\mathrm{R}$ residues) would, in principle, lead to less extensive protein degradation. The above results may be explained by the considerable modifications occur- 


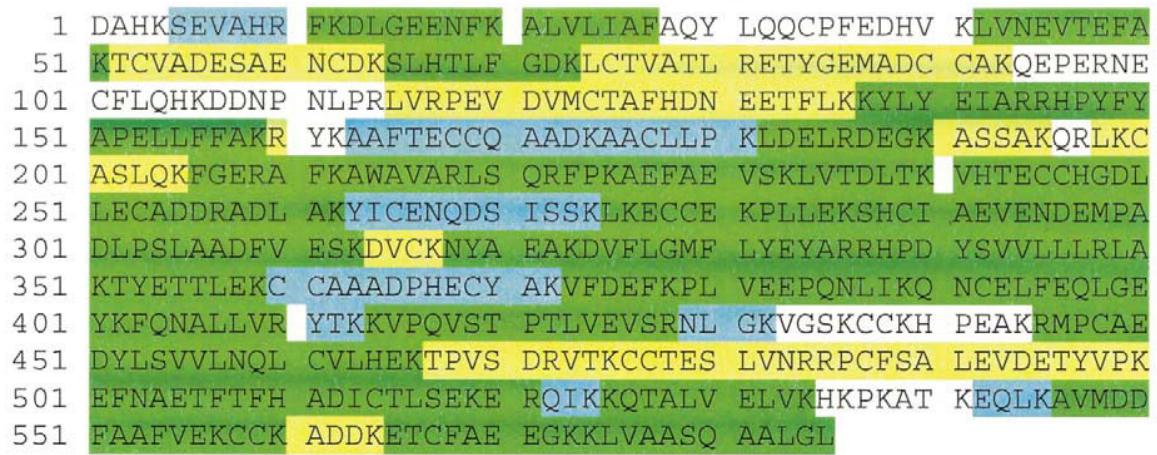

Colour code: AAA: sequences detected in the trypsin digestion mixture of unglycated HSA AAA: sequences detected in the Lys-C digestion mixture of unglycated HSA AAA: sequences detected in both the digestion mixtures of unglycated HSA

Figure 6. Peptides identified by ESI/LC/MS analyses of unglycated HSA.

ring in lysine residues after glycation, which reflects different enzyme activity.

The sequences identified in the Lys-C digest of glycated HSA are listed in Table 4, and it is interesting to note that some of identified peptides have already been detected in the case of trypsin digestion. On the basis of the specific behavior described above, MS/MS experiments are effective in discriminating between glucose-containing and unglycated peptides. These experiments yielded some unexpected data regarding production of peptides at $\mathrm{m} / \mathrm{z} 1124.0,1346.1$ and 1754.2. The first two species were identified as attributable to sequences 403-411 and 149-159 respectively, both originating from a cleavage at C-terminal $\mathrm{Y}$ residues, which have never been described as the cleavage site of Lys-C. The last one (at $\mathrm{m} / \mathrm{z}$ 1754.2) originates from the cleavage at $\mathrm{C}$-terminal $\mathrm{N}$ residue, a process already described in the literature [17] as unexpectedly activated by Lys-C and, in this particular case, present only in the digest of glycated HSA. The occurrence of these enzymatic cleavages is explained by modification of typical cleavage sites, due to glycation.

\section{Comparisons Between Trypsin and Lys-C Digestion Data}

The above results show that enzymatic digestion of glycated HSA by trypsin and Lys-C leads to a high

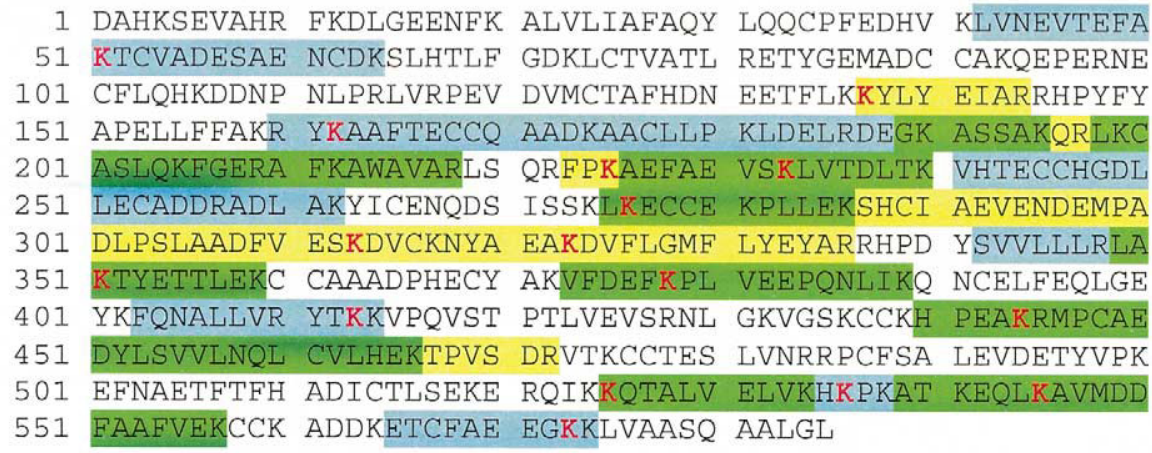

Colour code: AAA: glycated sequences detected in the trypsin digestion mixture of glycated HSA AAA: glycated sequences detected in the Lys-C digestion mixture of glycated HSA AAA: glycated sequences detected in both the digestion mixtures of glycated HSA K: $\quad$ glycated lysines

Figure 7. Glycated peptides identified by ESI/LC/MS analyses of glycated HSA. 


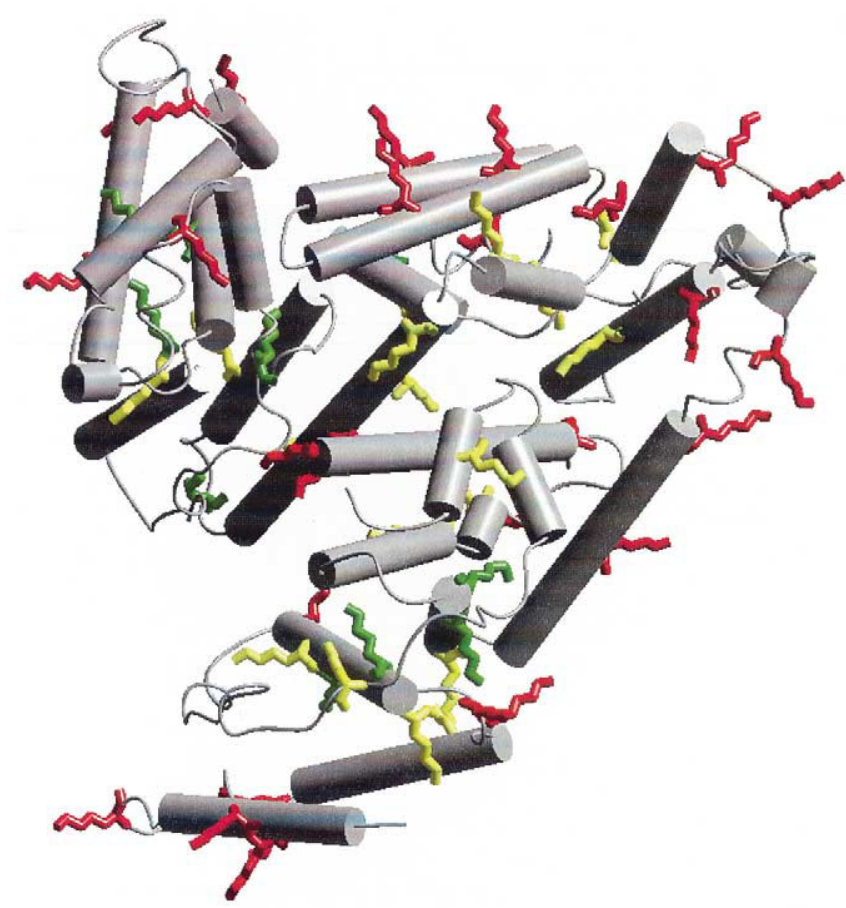

Figure 8. Most solvent-exposed lysine residues, color-coded according to their range of fractional solvent accessible surfaces (red: 0.5-1.0, most exposed; yellow: 0.3-0.5, less exposed; green: 0.10.3 , buried).

number of peptides, some of which are already present in the digestion mixture of unglycated HSA (and consequently not glycated species), whereas others are specific for the glycated protein. In the latter case, a further distinction must be made between glycated and unglycated peptides: the latter are due to different enzymatic cleavages of the glycated protein.

In order to identify possible AGE peptides generated by enzymatic digestion of glycated HSA, the data from the digestion mixtures of these substrates with the two different enzymes were compared, to highlight analogies and differences.

A description of these data is given on the basis of HSA sequence. Peptide mapping of glycated peptides identified in the digestion mixtures of glycated HSA only is shown in Figure 7. The same color codes as Figure 6 were employed. First of all, note that not all the K-sites have been glycated. In fact, the glycated peptides identified by both MALDI/MS and LC/ESI/MS cover only $54 \%$ of the whole protein. This result may be explained as due to two different phenomena: (1) A different enzymatic action on the glycated protein, which leads to preferential production of some glycated peptides; (2) the occurrence of favored glycation processes on specific lysine residues belonging to the protein chain. The data of Figure 7 indicate that at least 16 lysine residues belonging to the protein chain reacted with glucose, fitting the MALDI/MS measurements on the intact glycated protein, showing a mean glycation value of 14 .

It should be emphasized that a series of peptides are common to both enzymes and consequently may be considered, in pectore, as possible AGE peptides. Their mass value ranges from 1290 to $2208 \mathrm{Da}$, and some of them were already identified in the previous study performed by LC/FT-MS on glycated HSA [12].

The glycation sites are, in most cases, clearly identified and are labeled in red in Figure 7. The experimental data described above indicate that ${ }^{233} \mathrm{~K},{ }^{276} \mathrm{~K},{ }^{378} \mathrm{~K},{ }^{545} \mathrm{~K}$,

Table 5. Glycated K residues formed in the digestion of glycated HSA with trypsin and Lys-C and related fractional solvent accessible surface values

\begin{tabular}{|c|c|c|c|c|}
\hline $\begin{array}{l}\text { Glycated } \\
\text { residue }\end{array}$ & $\begin{array}{c}{[\mathrm{M}+\mathrm{H}]^{+} \text {of the peptide }} \\
\text { containing the glycated } \\
\text { residue in the } \\
\text { tryptic digest }\end{array}$ & $\begin{array}{c}{[\mathrm{M}+\mathrm{H}]^{+} \text {of the peptide }} \\
\text { containing the glycated } \\
\text { residue in the } \\
\text { Lys- } C \text { digest }\end{array}$ & $\begin{array}{l}\text { Fractional } \\
\text { solvent } \\
\text { accessible } \\
\text { surface }\end{array}$ & \\
\hline${ }^{313} \mathrm{~K}$ & 3523.9 & & 0.881 & $\operatorname{Red}^{a}$ \\
\hline${ }^{233} \mathrm{~K}$ & 1812.9 & 1813.2 & 0.779 & Red $^{a}$ \\
\hline${ }^{573} \mathrm{~K}$ & & 1285.0 & 0.777 & $\operatorname{Red}^{\mathrm{a}}$ \\
\hline${ }^{51} \mathrm{~K}$ & & 2676.6 & 0.713 & $\operatorname{Red}^{a}$ \\
\hline${ }^{276} \mathrm{~K}$ & 1592.7 & 1594.2 & 0.645 & $\operatorname{Red}^{\mathrm{a}}$ \\
\hline 444 & & 3284.0 & 0.623 & $\operatorname{Red}^{\mathrm{a}}$ \\
\hline${ }^{378} \mathrm{~K}$ & 2207.6 & 2208.4 & 0.610 & Red $^{a}$ \\
\hline${ }^{225} \mathrm{~K}$ & $1396.5 ; 2185.8$ & & 0.565 & $\operatorname{Red}^{a}$ \\
\hline${ }^{323} \mathrm{~K}$ & 2462.8 & & 0.535 & $\operatorname{Red}^{a}$ \\
\hline${ }^{351} \mathrm{~K}$ & 1458.7 & 4514.5 & 0.476 & Yellow $^{a}$ \\
\hline${ }^{137} \mathrm{~K}$ & 1198.7 & & 0.474 & Yellow $^{a}$ \\
\hline${ }^{536} \mathrm{~K}$ & & 970.9 & 0.425 & Yellow ${ }^{a}$ \\
\hline${ }^{162} \mathrm{~K}$ & & 1866.4 & 0.417 & Yellow ${ }^{a}$ \\
\hline${ }^{545} \mathrm{~K}$ & 2003.0 & 2004.4 & 0.347 & Yellow \\
\hline${ }^{525} \mathrm{~K}$ & 1290.7 & 1291.0 & 0.337 & Yellow \\
\hline${ }^{413} \mathrm{~K}$ & & 1626.0 & 0.197 & Green $^{a}$ \\
\hline
\end{tabular}

aColor code: Red $=$ more exposed: $0.5-1.0 ;$ Yellow = less exposed: $0.3-0.5 ;$ Green $=$ buried: $0.1-0.3$. 
and ${ }^{525} \mathrm{~K}$ are privileged glycation sites. To obtail further support to these results, a molecular modeling study was undertaken in order to identify the most exposed lysine residues, necessarily more available to possible glycation processes.

The structure of HSA is shown in Figure 8, in which the different lysine residues are evidenced and colorcoded with respect to SAS values. These theoretical values are compared with the experimental ones in Table 5, showing generally good agreement between the two findings, as most of the identified glycation sites are sufficiently exposed to be prone to react with glucose. However, some discrepancies appear, e.g., those related to glycated residues ${ }^{545} \mathrm{~K},{ }^{525} \mathrm{~K}$, and ${ }^{413} \mathrm{~K}$, which are detected even though their SAS values are particularly low. This result may be due to an at least partial tertiary structural modification of the protein, induced by glycation and/or by acid catalysis [18].

At this point, it becomes interesting to compare our data with those from previous researches on in vivo glycated sites of HSA. Garlick and Mazer [18] showed that the predominant glycation site of HSA in vivo is ${ }^{525} \mathrm{~K}$, whereas in vitro incubation of HSA with glucose [19] indicates that a different amino acid, ${ }^{199} \mathrm{~K}$, is glycated. Later, this result was partially confirmed by Iberg and Fluckiger [20], who determined that in vivo glycated HSA shows that glucose condenses on ${ }^{199} \mathrm{~K}$, ${ }^{281} \mathrm{~K},{ }^{439} \mathrm{~K}$, and ${ }^{525} \mathrm{~K}$. Evidence for the assignment of five other sites was less certain, but consistent with glycation at ${ }^{233} \mathrm{~K},{ }^{317} \mathrm{~K},{ }^{351} \mathrm{~K},{ }^{12} \mathrm{~K}$ and ${ }^{534} \mathrm{~K}$. However, it was shown that approximately $33 \%$ of total glycation occurs at ${ }^{525} \mathrm{~K}$.

In our case, the high glucose concentration employed for HSA incubation leads to more extensive glycation of the protein, reflecting the production, by enzymatic digestion, of a higher number of glycated peptides. It is worth noting that some of the glycation sites observed in the present study are the same as those determined in in vivo experiments, and consequently indicate that the presence of AGE peptides containing those lysine residues is to be expected.

\section{Conclusion}

In conclusion, among the trypsin and Lys-C enzymatic digestion products, the present study identified some glycated peptides, some of which are common to the two digestion mixtures. Molecular modeling and experimental data are mostly in agreement, indicating that these glycated peptides contains lysine residues exhibiting high solvent accessible surface values.

In our opinion, these data are a good starting point to investigate the presence of these peptides in human plasma from healthy, diabetic and nephropathic subjects, in order to confirm their nature as AGE peptides.

\section{References}

1. Maillard, L C. Action des acides aminés sur le sucres: formation des mélanoidines per voie méthodique. C. R. Acad. Sci. 1912, 154, 66-68.

2. Vlassara, H.; Bucala, R.; Stiker, L. Pathogenic Effects of Advanced Glycosylation: Biochemical, Biologic, and Clinical Implication for Diabetes and Aging. Lab. Invest. 1991, 70, $138-151$.

3. Lyons, T. J.; Jenkins, A. Glycation, Oxidation, and Lipooxidation in the Development of the Complications of Diabetes: A Carbonyl Stress Hypothesis. I. Diab. Rev. 1997, 5, 365-391.

4. Thornalley, P. J. The Clinical Significance of Glycation. Clin. Lab. 1999, 45, 263-273.

5. Brownlee, M.; Vlassara, H.; Cerami, A. Nonenzymatic Glycosylation and the Pathogenesis of Diabetic Complications. Ann. Intern. Med. 1984, 101, 527-537.

6. Brownlee, M. Lilly Lecture 1993. Glycation and Diabetic Complications. Diabetes 1994, 43, 836-841.

7. (a) Bucala, R.; Makita, Z.; Vaga, G.; Grundy, S.; Kshinsky, T.; Cerami, A.; Vlassara, H. Modification of Low Density Lipoprotein by Advanced Glycation End Products Contributes to Dyslipidemia of Diabetes and Renal Insufficiency. Proc. Natl. Acad. Sci. U.S.A. 1994, 91, 9441-9445. (b) Gugliucci, A.; Menini, T. Circulating Advanced Glycation Peptides in Streptozotocin-Induced Diabetic Rats: Evidence for Preferential Modification of IgG Light Chains. Life Sci. 1998, 62, 2141-2150.

8. (a) Horiuchi, S.; Higashi, T.; Ikeda, K.; Saishoji, T.; Jinnouchi, Y.; Sano, H.; Shibayama, R.; Sakamoto, T.; Araki, N. Advanced Glycation End Products and Their Recognition by Macrophage and Macrophage-Derived Cells. Diabetes 1996, 45, S73S76. (b) Dean, R. T. Lysosomal Enzymes as Agents of Turnover of Soluble Cytoplasmatic Proteins. Eur. J. Biochem. 1975, 58, 9-14. (c) Skolnik, E. Y.; Yang, Z.; Makita, Z.; Radoff, S.; Kirkstein, M.; Vlassar, H. Human and Rat Mesangial Cell Receptors for Glucose-Modified Proteins: Potential Role in Kidney Tissue Remodeling and Diabetic Nephropathy. J. Exp. Med. 1991, 174, 931-939.

9. (a) Ritz, E.; Deppisch, R.; Nawroth, P. Toxicity of Uraemia: Does it Come of AGE? Nephrol. Diel. Transplant. 1994, 9, 1-2. (b) Korbert, S. M.; Makita, Z.; Firanek, C. A.; Vlassara, H. Advanced Glycolsylation End Products in Continuous Ambulatory Peritoneal Dialysis Patients. Am. J. Kidney Dis. 1993, 22, 588-591.

10. Gugliucci, A.; Bendayan, M. Renal Fate of Circulating Advanced Glycation End Products (AGE): Evidence for Reabsorption and Catabolism of AGE-Peptides by Renal Proximal Tubular Cells. Diabetologia 1996, 39, 149-160.

11. Lapolla, A.; Fedele, D.; Senesi, A.; Aricò, N. C.; Reitano, R.; Favretto, D.; Seraglia, R.; Astner, H.; Traldi, P. Advanced Glycation End Products/Peptides: A Preliminary Investigation by LC and LC/MS. Il Farmaco 2002, 57, 845-852.

12. Marotta, E.; Lapolla, A.; Fedele, D.; Senesi, A.; Reitano, R.; Witt, M.; Seraglia, R.; Traldi, P. Accurate Mass Measurements by Fourier Transform Mass Spectrometry in the Study of Advanced Glycation End Products/Peptides. J. Mass Spectrom. 2003, 38, 196-205.

13. Berman, H. M.; Westbrook, J.; Feng, Z.; Gilliland, G.; Bhat, T. N.; Weissing, H.; Shindyalov, I. N.; Bourne, P. E. The Protein Data Bank. Nucleic Acids Res. 2000, 28, 235-242 (http://www.rcsb.org/pdb/).

14. Schnider, S. L.; Kohn, R. R. Effects of Age and Diabetes Mellitus on the Solubility of Collagen from Human Skin, Tracheal Cartilage, and Dura Mater. Exp. Gerontol. 1982, 17, 185-194. 
15. March, R. E.; Todd, J. F. J., Eds.; Practical Aspects of Ion Trap Mass Spectrometry, Vols. I and II; CRC Press: Boca Raton, FL, 1995.

16. Jeno, P.; Mini, T.; Moes, S.; Hintermann, E.; Horst, M. Internal Sequences from Protein Digested in Polyacrylamide Gels. Anal. Biochem. 1995, 224, 75-82.

17. Perides, G.; Kuhn, S.; Scherbarth, A.; Traub, P. Probing of Structural Stability of Vimentin and Desmin-Type Intermediate Filaments with Calcium Activated Proteinase, Thrombin, and Lysine-Specific Endoproteinase Lys-C. Eur. J. Cell Biol. 1987, 43, 450-458.

18. Garlick, R. L.; Mazer, J. S. The Principal Site of Nonenzymatic Glycosylation of Human Serum Albumin In Vivo. J. Biol. Chem. 1983, 258, 6142-6146.

19. Day, J. F.; Thorpe, S. R.; Baynes, J. W. Nonenzymatically Glycosylated Albumin. J. Biol. Chem. 1979, 254, 595-597.

20. Iberg, N.; Fluckiger, R. Nonenzymatic Glycosylation of Albumin in Vivo. J. Biol. Chem. 1986, 261, 13542-13545. 